\title{
Outcomes in IVF Conceived Pregnancies Complicated with Hypertensive Disorders
}

\author{
Krasniqi MV' ${ }^{1}$ Daka $Q^{2}$
}

\begin{abstract}
Introduction: Many studies have demonstrated an increased risk of obstetrical and neonatal complications after assisted reproductive techniques treatment compared to spontaneously conceived pregnancies. There are no data regarding these outcomes in Kosovo. The aim of our study was, to compare maternal, obstetric and neonatal parameters of in-vitro fertilization (IVF) conceived pregnancies complicated with hypertensive disorders (HD) versus uncomplicated spontaneous conceived pregnancies in Kosovo. Material and Methods: This observational study was undertaken at the Department of Gynaecology, University Clinical Centre of Kosova, during a two year period. A total of 104 pregnant women were included in the study. Maternal, obstetrical and neonatal parameters in both groups were assessed and compared. Statistical analysis was performed using SPSS 22.0 statistical software. Results:Women that conceived through IVF and had HD during pregnancy were older $(p=0.0001)$, primipara $(p=0.007)$, had multiple pregnancies $(p=0.0001)$ and had worse obstetrical outcomes including cervix insufficiency $(p=0.0001)$, premature rupture of membranes $(p=0.0001)$, and delivery type $(p=0.003)$ compared to women that conceived spontaneously. The only statistically significant differences in neonatal outcomes were in the $\operatorname{Apgar} 1^{\text {st }}(p=0.012)$ and $\operatorname{Apgar}^{\text {th }}(p=0.004)$ scores that were higher among babies born from mothers that conceived through IVF and had HD during pregnancy. Conclusions: Results of our study are in line with the results from other countries in regards to maternal demographic profile, except education level and employment, and obstetrical outcomes. However, there were no differences in regards to neonatal outcomes between the two groups of babies other than in the Apgar $1^{\text {st }}$ and Apgar $5^{\text {th }}$ scores.
\end{abstract}

Key words: Hypertensive disorders, IVF, Kosovo, Outcomes.
${ }^{1}$ Dr. Merita Vuniqi Krasniqi, MD, Fellow Gynaecology and Obstetrics, Teaching Assistant, Department of Gynaecology, UCCK; Medical Faculty, University of Prishtina, Prishtinë, Kosovo, ${ }^{2}$ Dr. Qëndresë Daka, MD, Teaching Assistant, Department of Pathophysiology, Medical Faculty, University of Pristina, Prishtinë, Kosovo.

\author{
Address for correspondence \\ Qëndresë Daka (Teaching Assistant) \\ Department of Pathophysiology \\ University Clinical Centre of Kosovo- Medical \\ Faculty, \\ 10000 Pristine, Kosovo; \\ Tel No; ++ 381385006002042 \\ E-mail: qendrese@hotmail.com
}

Acknowledgements: We acknowledge Dr. Sanije Gashi for her contribution on statistical analysis.

Funding: Nil

Conflict of Interest: None

Permission from IRB: Yes

How to cite

Krasniqi MV, Daka Q. Outcomes in IVF Conceived Pregnancies Complicated with Hypertensive Disorders. J Nepal Paediatr Soc 2017;37(2):159-163.

doi:http://dx.doi.org/10.3126/jnps.v37i2.16989

\section{Introduction}

$S_{s}$ ince the introduction of the in-vitro fertilization (IVF) treatment, the success rate of the procedure has been increased and most of the pregnancies after IVF result in normal healthy outcomes. However, the risk for a number of obstetric and neonatal complications due to these treatments remains unknown. Many studies on this topic report
This work is licensed under a Creative Commons Attribution 3.0 License. 
for an increased risk of: hypertensive disorders (HD), preterm delivery, placental abruption, placenta previa.

C-section delivery, low and very low birth weight (LBW and VLBW), congenital malformations, and neonatal mortality compared to spontaneously conceived pregnancies ${ }^{1,2,3,4}$. The association of these complications to IVF treatment procedures can be explained partly by the high rate of multiple pregnancies and advanced maternal age, but also by the impact of technique, culture systems and medications used for treatment ${ }^{5,6,7}$.

On the other hand, HD during pregnancies (chronic hypertension; gestational hypertension; preeclampsia; eclampsia; or HELLP syndrome), the most common medical problems encountered in pregnancy, remain an important cause of maternal and fetal morbidity and mortality ${ }^{8,9,10,11}$. Data from observational studies demonstrate that $\mathrm{HD}$ during pregnancies are also associated to an increased risk of: preterm delivery, placental abruption, C-section, LBW and VLBW, neonatal morbidities or mortality ${ }^{10,12,13,14}$. Worldwide, several risk factors have been described to be associated to HD during pregnancy such as: family history for HD in pregnancy or previous HD in pregnancy, extremes of maternal age, nuliparity, obesity, diabetes,chronic hypertension, multiple pregnancies etc. ${ }^{15}$. Beside other risk factors, IVF treatment technology appears to be one of the most important risk factors for occurrence of HD during pregnancy ${ }^{16,17}$

Although there is a large body of literature that describes the effect of IVF treatment on HD during pregnancy and association of both IVF treatment and $\mathrm{HD}$ to adverse maternal and neonatal outcomes, little is done to asses these associations in the Republic of Kosovo. Therefore, the aim of our study was, was to compare maternal characteristics, obstetric and neonatal outcomes of IVF conceived pregnancies complicated with HD versus uncomplicated spontaneous conceived pregnancies in Kosovo.

\section{Material and Methods}

This observational comparative study was undertaken at the Department of Gynaecology, University Clinical Centre of Kosovaduring a two year period, from January 2014-December 2015. The study was approved by the institutional ethical committee and informed consent was taken from mothers.

A total of 104 pregnant women were included, 54 pregnant women that conceived through IVF procedures and had HD during pregnancy (Group I) and 80 pregnant women that conceived spontaneously and had no HD during pregnancy (Group II). Diagnoses of $\mathrm{HD}$ in pregnant women were set based on the criteria of the National High Blood Pressure Education Program Working Group ${ }^{8}$.

Baseline maternal characteristics were collected by nurse and included: age, education, parity and multiple pregnancies. Gynaecologist collected obstetrical and neonatal outcomes data including: cervical cerclage, premature rupture of membranes (PROM), type of delivery, preterm birth, gestational age, neonatal birth weight and Apgar score.

Maternal, obstetrical and neonatal data of IVF conceived pregnancies complicated with HD were compared to uncomplicated spontaneously conceived pregnancies using chi-squared or Fisher's exact tests for categorical variables and students t-tests for continuous variables. Categorical variables were expressed as percentages and continuous variables were expressed as mean $\pm \mathrm{SD}$ (median). Statistical analysis was performed using SPSS 22.0 statistical software. Statistical significance was indicated by a $p$ value < 0.05 , whereas values of $p<0.001$ were considered as highly significant.

\section{Results}

A total of 104 pregnant women and 157 children were included in our data analysis. The detailed description of maternal demographic profile is presented in Table 1.Pregnant women that conceived through IVF treatment technology and had HD during pregnancy were older compared to women that conceived spontaneously and had no HD during pregnancy $(39.7 \pm 7.8$ years vs. $32 \pm 5.9$ years) and this difference was highly statistically significant $(p=0.0001)$. The majority of women in both groups were housewives (74\%) and no difference, in between the two groups, was found in regard to working conditions. In regard to parity and multiple pregnancies, the difference in between the two groups was highly statistically significant. Primpara were $87 \%$ of women that conceived through IVF treatment technology and had $\mathrm{HD}$ during pregnancy compared to $67.5 \%$ of women that conceived spontaneously and had no HD during pregnancy $(p=0.007)$. Whereas, $42.6 \%$ of women in the IVF group delivered twins or other multiples compared to $2.5 \%$ of women that conceived spontaneously $(p=0.0001)$.

Obstetrical and neonatal outcomes of the study population are presented in Table 2.Women that conceived through IVF treatment technology and had HD during pregnancy showed statistically significantly more frequent pregnancy complications in regard to cervix insufficiency, premature rupture of membranes and 
Table 1: Maternal demographic profile

\begin{tabular}{|c|c|c|c|}
\hline Maternal characteristics & $\begin{array}{c}\text { Group I } \\
54(40.3 \%)\end{array}$ & $\begin{array}{c}\text { Group II } \\
80(59.7 \%)\end{array}$ & $p$-value \\
\hline Age & $39.7 \pm 7.8(\mathrm{SD})$ & $32.0 \pm 5.9(\mathrm{SD})$ & $p=0.0001^{* *}$ \\
\hline \multicolumn{4}{|l|}{ Work } \\
\hline Housewife & $40(74.1 \%)$ & $67(83.8 \%)$ & $p=0.250$ \\
\hline Worker & $14(25.9 \%)$ & $12(15.0 \%)$ & \\
\hline Student & 1 & $1(1.3 \%)$ & \\
\hline \multicolumn{4}{|l|}{ Parity } \\
\hline 1 & $47(87.0 \%)$ & $54(67.5 \%)$ & $p=0.007^{* *}$ \\
\hline II & $2(3.7 \%)$ & $19(23.8 \%)$ & \\
\hline $\mathrm{III+}$ & $5(9.3 \%)$ & $7(8.8 \%)$ & \\
\hline \multicolumn{4}{|l|}{ Multiple pregnancies } \\
\hline 1 & $31(57.4 \%)$ & $78(97.5 \%)$ & $p=0.0001^{* *}$ \\
\hline II & $22(40.7 \%)$ & $2(2.5 \%)$ & \\
\hline $\mathrm{III+}$ & $1(1.9 \%)$ & I & \\
\hline
\end{tabular}

Group I = women that conceived thorough IVF procedures and had hypertensive complications during pregnancy. Group II = women that conceived spontaneously and had no hypertensive complications during pregnancy. PROM=Premature Rupture of Membranes. Data are presented as the Mean \pm SD and as N (\%). Values of $p<0.05^{*}$ were considered significant and $p<0.001^{* *}$ as highly significant.

Table 2: Obstetrical and neonatal outcomes of study population

\begin{tabular}{|c|c|c|c|}
\hline $\begin{array}{l}\text { OBSTETRICAL } \\
\text { OUTCOMES }\end{array}$ & $\begin{array}{c}\text { Group I } \\
54(40.3 \%)\end{array}$ & $\begin{array}{c}\text { Group II } \\
80(59.7 \%)\end{array}$ & $p$-value \\
\hline Cervix insufficiency & $8(14.8 \%)$ & $0(0 \%)$ & $p=0.0001^{*}$ \\
\hline PROM & $4(7.4 \%)$ & $0(0 \%)$ & $p=0.0001^{*}$ \\
\hline C-section delivery & $50(92.6 \%)$ & $53(66.3 \%)$ & $p=0.003^{*}$ \\
\hline NEONATAL OUTCOMES & 75 & 82 & \\
\hline \multicolumn{4}{|l|}{ Gender } \\
\hline Male & $35(46.7 \%)$ & $45(54.9 \%)$ & $p=0.385$ \\
\hline Female & $40(53.3 \%)$ & $37(45.1 \%)$ & \\
\hline Mean Gestational Age & $36.1 \pm 2.2(\mathrm{SD})$ & $35.9 \pm 3.6(\mathrm{SD})$ & $p=0.716$ \\
\hline Preterm births & $29(53.7 \%)$ & $35(43.8 \%)$ & $p=0.339$ \\
\hline Birth weight & $2644 \pm 722.7$ (SD) & $2730 \pm 1014.3(S D)$ & $p=0.054$ \\
\hline \multicolumn{4}{|l|}{ Apgar score } \\
\hline Minute 1 & 7. $0 \pm 1.7(\mathrm{SD})$ & $6.2 \pm 2.2(\mathrm{SD})$ & $p=0.012^{*}$ \\
\hline Minute 5 & $8.4 \pm 0.8(\mathrm{SD})$ & $7.9(0.9) \pm 0.9(\mathrm{SD})$ & $p=0.004^{*}$ \\
\hline
\end{tabular}

Group I = women that conceived thorough IVF procedures and had hypertensive complications during pregnancy. Group II = women that conceived spontaneously and had no hypertensive complications during pregnancy. PROM=Premature Rupture of Membranes. Data are presented as the Mean \pm SD and as N (\%). Values of $p<0.05^{*}$ were considered significant and $p<0.001^{* *}$ as highly significant.

delivery type. Cervix insufficiency and premature rupture of membranes were not noted in between uncomplicated spontaneously conceived pregnancies in compare to IVF conceived pregnancies that were complicated with HD during pregnancy where cervix insufficient occurred in $14.8 \%$ of cases and premature rupture of membranes in $7.4 \%$ of cases, therefore there was a highly statistical significance in between the two groups $(p=0.0001)$. The percentage of women that delivered by $\mathrm{C}$-section was $92.6 \%$ in the IVF group compared to $66.3 \%$ in the group that conceived spontaneously $(p=0.003)$. Although, the percentage of women that delivered preterm was higher in the group that conceived through IVF technology and had HD during pregnancy $(56.3 \%)$, the difference with the group that conceived spontaneously (46.3\%) was not statistically significant $(p=0.339)$. Women that conceived through IVF procedures and had HD during pregnancy delivered 75 (35 F/40 M) infants, whereas those that conceived spontaneously and had no HD during pregnancy delivered $82(45 \mathrm{~F} / 37 \mathrm{M})$ infants. There was no difference when compared for infants' gender in between the two groups $(p=0.385)$. We also found 
that there was no statistical difference between the two groups of babies when compared for gestational age and birth weight. Mean gestational age of babies born from mothers that conceived through IVF technology was $36.1 \pm 2.2$ weeks compared to babies that were born from mothers that conceived spontaneously $35.9 \pm 3.6$ weeks $(p=0.716)$, whereas mean birth weight of babies born from mothers that conceived through IVF technology and had HD during pregnancy was $26440 \pm 722.7 \mathrm{~g}$ compared to babies that were born from mothers that conceived spontaneously $2730 \pm 1014.3 \mathrm{~g}(p=0.054)$. Mean Apgar $1^{\text {st }}$ and Apgar $5^{\text {th }}$ indices were significantly higher within the babies born from mothers that conceived through IVF technology and had HD during pregnancy.

Mean Apgar $1^{\text {st }}$ and Apgar $5^{\text {th }}$ scores of babies born from mothers that conceived through IVF procedures were $7.0 \pm 1.7$ and $8.4 \pm 0.8$ scores, respectively compared to those of babies born from mothers that conceived spontaneously that had a mean Apgar $1^{\text {st }}$ of $6.2 \pm 2.2$ scores and mean Apgar $5^{\text {th }}$ of $7.9 \pm 0.9$ scores (Apgar $1^{\text {st }} p=0.012$, Apgar $\left.5^{\text {th }} p=0.004\right)$.

\section{Discussion}

According to the $\mathrm{WHO}$, infertility and sterility will be the third-most serious disease worldwide in the 21 st century, and the practice of IVF treatment will be increased ${ }^{18}$. On the other hand, HD remains the most common medical problem encountered during pregnancy that tends to increase more due to recent changes in the antenatal population ${ }^{10}$. The increasing use of IVF technology for infertility treatmentand increased tendency for occurrence of HD during pregnancy due to this treatment, makes their obstetric and neonatal outcome aspects an important public health concern ${ }^{19}$. However, despite the worldwide spread of the problem, data from studies remain controversial due to differences in study designs, populations and countries. Although, Kosovo, a post-conflict country, has the youngest population in Europe, the growth rate of its population started to slow, and the birth rate is reduced as a consequence of the increased rate of infertility ${ }^{20}$. Due to specific social and cultural characteristics of the Kosovo society to maintain a family structure we assume that, with this trend of infertility, the number of women that conceive through IVF procedures will be increased. To the best of our knowledge, this is the first study to investigate the maternal, obstetric and neonatal characteristics of IVF conceived pregnancies complicated with HD versus uncomplicated spontaneous conceived pregnancies in Kosovo. Data from this study will help determine the size and burden of the problem and serve to develop specific national prevention measure for HD in IVF conceived pregnancies.
Our analysis was carried out on 54 cases and 80 controls. In line with the results from other countries, women that conceived through IVF technology treatment and had HD during pregnancy were older $(p=0.0001)$, primipara $(p=0.007)$ and had multiple pregnancies $(p=0.0001)$ compared to women that conceived spontaneously and had no HD during pregnancy, however, we found no difference in between the two groups of pregnant women in regard to education level and employment as the majority of pregnant women in both groups were housewives ${ }^{15,16,17,19}$.

Obstetrical and neonatal outcomes of the group that conceived through IVF technology treatment and had HD during pregnancy compared to those of the group that conceived spontaneously and had no HD during pregnancy varied.Women that conceived through IVF treatment technology and had HD during pregnancy showed statistically significantly more frequent pregnancy complications in regard to cervix insufficiency $(p=0.0001)$, premature rupture of membranes $(p=0.0001)$, and delivery type $(p=0.003)$ in compare to women that conceived spontaneously. However, we found moderate differences in neonatal outcomes of babies born from the two groups of mothers. Although babies born from mothers that conceived through IVF technology and had HD during pregnancy had lower birth weight $(86 \mathrm{~g})$; longer gestational age $(0.2$ weeks) and were born preterm (10\%) in compare to those born from mothers that conceived spontaneously, this difference was not statistically significant. The differences in between the two groups of babies were highly statistically significant only for the Apgar $1^{\text {st }}$ and Apgar $5^{\text {th }}$ scores. Mean Apgar $1^{\text {st }}$ and Apgar $5^{\text {th }}$ scores of babies born from mothers that conceived through IVF technology were 7.0 and 8.4 respectively compared to those of babies born from mothers that conceived spontaneously 6.2 for Apgar 1 and 7.9 for Apgar 5 ( $p=0.012$ and $p=0.004$, respectively).

\section{Conclusion}

The results of our study are in line with the results from other countries in regard to maternal demographic profile, beside education level and employment, and obstetrical outcomes. Obstetrical outcomes of women that conceived through IVF treatment technology and had HD during pregnancy were worse compared to those of women that conceived spontaneously.

\section{Limitations}

Our results could be a prone to several limitations due to the study design. Large cohort prospective studies, controlled for confounders, are necessary to confirm our findings. 


\section{References}

1. Shevel T, Malone FD, Vidaver J, Porter $\mathrm{TF}$, Luthy DA, Comstock $\mathrm{CH}$ et al. Assisted reproductive technology and pregnancy outcome. ObstetGynecol2005;106(5):1039-45.DOI: 10.1097/01. AOG.0000183593.24583.7c.

2. Buckett WM, Chian RC, Holzer H, Dean N, Usher $\mathrm{R}$, Tan SL. Obstetric outcomes and congenital abnormalities after in vitro maturation, in vitro fertilization, and intrazytoplasmatic sperm injection. ObstetGynecol2007;110(4):885-91. DOI:10.1097/01. AOG.0000284627.38540.80.

3. Wisborg $\mathrm{K}$, Ingerslev $\mathrm{HJ}$, Henriksen TB. In vitro fertilization and preterm delivery, low birth weight, and admission to the neonatal intensive care unit: a prospective follow-up study. FertilSteril2010;94(6):2102-6. DOI: 10.1016/j. fertnstert.2010.01.014.

4. Mukhopadhaya N, Arulkumaran S Reproductive outcomes after in-vitro fertilization. CurrOpinObstetGynecol2007;19(2):113-9. DOI: 10.1097/GCO.0b013e32807fb199.5.

5. Nouri K, Ott J, Stoegbauer L, Pietrowski D, Frantal $S$, Walch K.Obstetric and perinatal outcomes in IVF versus ICSI-conceived pregnancies at a tertiary care center--a pilot study. ReprodBiolEndocrinol 2013;11:84. DOI: 10.1186/1477-7827-11-84.

6. Finnström $O$, Källén $B$, Lindam A, Nilsson $E$, Nygren $K G$, Olausson PO. Maternal and child outcome after in vitro fertilization - a review of 25 years of populationbased data from Sweden. ActaObstetGynecol Scan2011;90(5):494-500. DOI: 10.1111/j.16000412.2011.01088.x.

7. Wen J, Jiang J, Ding C, Dai J, Liu Y, Xia Y et al. Birth defects in children conceived by in vitro fertilization and intracytoplasmatic sperm injection: a meta-analysis. FertilSteril2012;97(6):1331-7.DOI: $\quad$ 10.1016/j. fertnstert.2012.02.053.

8. National High Blood Pressure Education Program Working Group on High Blood Pressure in Pregnancy. Report of the National High Blood Pressure Education Program Working Group on High Blood Pressure in Pregnancy. Am J ObstetGynecol 2000;183(1):S1-S22. DOI: $10.1067 / \mathrm{mob} .2000 .107928$.

9. American College of Obstetricians and Gynaecologists, Task Force on Hypertension in Pregnancy. Hypertension in pregnancy. Report of the American College of Obstetricians and Gynaecologists' Task Force on Hypertension in Pregnancy. ObstetGynecol 2013;122 (5):1122-31. DOI: 10.1097/01. AOG.0000437382.03963.88.
10. Bramham K, Parnell B, Nelson-Piercy C, Seed PT, Poston L, Chappell LC. Chronic hypertension and pregnancyoutcomes: systematic review and metaanalysis.Brit Med J 2014 15;348:g2301. DOI: 10.1136/ bmj.g2301.

11. Duley L. Pre-eclampsia and the hypertensive disorders of pregnancy. Br Med Bull 2003;67:161-76. DOI: 10.1093/bmb/ldg005.

12. Sachan $R$, Patel ML, Sachan $P$, Gaurav A, Singh $M$, Bansal B.Outcomes in hypertensive disorders of pregnancy in the North Indian population. Int J Womens Health 2013;5:101-8.DOI: 10.2147/IJWH S40473.

13. Yadav S, Saxena U, Yadav R, Gupta S.Hypertensive disorders of pregnancy and maternal and fetal outcome: a case controlled study.J Indian Med Assoc 1997;95(10):548-51.

14. Dalmáz CA, Santos KG, Botton MR, Roisenberg I. Risk factors for hypertensive disorders of pregnancy in southern Brazil.Rev Assoc Med Bras (1992). 2011;57(6):692-6.DOI: 10.1590/S010442302011000600018.

15. Poon LC, Kametas NA, Chelemen T, Leal A, Nicolaides KH.Maternal risk factors for hypertensive disorders in pregnancy: a multivariate approach. J Hum Hypertens 2010;24(2):104-10. DOI: 10.1038/jhh.2009.45.

16. Watanabe N, Fujiwara T, Suzuki T, Jwa SC, Taniguchi $\mathrm{K}$, Yamanobe $\mathrm{Y}$ et al. Is in vitro fertilization associated with preeclampsia? A propensity score matched study. BMC Pregnancy Childbirth 2014;14:69. DOI:10.1186/1471-2393-14-69.

17. Thomopoulos C, Tsioufis C, Michalopoulou H, Makris T, Papademetriou V, Stefanadis C.Assisted reproductive technology and pregnancy-related hypertensive complications: a systematic review. J Hum Hypertens 2013;27(3):148-57. DOI: 10.1038/jhh.2012.13.

18. Qiao J, Feng HL. Assisted reproductive technology in China: compliance and non-compliance. Trans/Pediatr 2014;3(2):91-7. DOI: 10.3978/j.issn.22244336.2014.01.06.

19. Opdahl S, Henningsen AA, Tiitinen A, Bergh C, Pinborg A, Romundstad PR et al. Risk of hypertensive disorders in pregnancies following assisted reproductive technology: a cohort study from the CoNARTaS group. Hum Reprod 2015;30(7):1724-31. DOI:10.1093/humrep/dev090.

20. Elezaj S, Gashi Z, Zeqiraj A, Grabanica D, Shllaku A, Gruda B, et al. Treatment of Infertility in Men with Posttraumatic Stress Disorder (PTSD) with the Method of Intrauterine Insemination. Med Arch 2015;69(5):32730.DOI: 10.5455/medarh.2015.69.327-330. 